\title{
Estudantes de primeira geração (P-Ger) na educação superior brasileira: analisando os dados da PNS - 2013
}

\section{First-Generation Students (F-Gen) in Brazilian Higher Education: analyzing data from PNS - 2013}

\author{
Marília Morosini* \\ Vera Lucia Felicetti**
}

\begin{abstract}
RESUMO
O presente artigo, com olhar prospectivo, reflete acerca do novo perfil estudantil na educação superior, mais atentamente ao estudante de primeira geração (P-Ger). Para tal, discute, inicialmente, com fundamento em pesquisa bibliográfica, o conceito de estudante de primeira geração (P-Ger) e suas características. Num segundo momento, são analisados, de forma inédita, dados sobre os P-Ger, em fonte oficial da Pesquisa Nacional da Saúde PNS - do Instituto Brasileiro de Geografia e Estatística - IBGE - de 2013. São levantadas considerações quanto à inclusão dos P-Ger na educação superior do país, destacando o processo de colaboração institucional para a minimização das tensões entre dominantes e dominados no campo científico.

Palavras-chave: Estudante de primeira geração. P-Ger. Educação superior. PNS/IBGE.
\end{abstract}

\footnotetext{
ABSTRACT

This article reflects upon the new student profile in Higher Education with a prospective view, particularly the First-Generation Student (F-Gen). To this

* Pontifícia Universidade Católica do Rio Grande do Sul. Programa de Pós-graduação em Educação. Porto Alegre, Rio Grande do Sul, Brasil. E-mail: mariliamorosini@hotmail.com. http:// orcid.org/0000-0002-2433-5783.

** Unilasalle. Programa de Pós-graduação em Educação. Canoas, Rio Grande do Sul, Brasil. E-mail: vera.felicetti@unilasalle.edu.br. http://orcid.org/0000-0001-6156-7121.
} 
end, we initially discuss the foundations of the concept of a 1st-generation student (F-Gen) and their characteristics, based on a bibliographic survey. Moreover, data on F-Gens are analyzed for the first time from the official source of the National Health Survey (Pesquisa Nacional da Saúde - PNS) from the Brazilian Institute of Geography and Statistics (Instituto Brasileiro de Geografia e Estatística - IBGE) from 2013. Considerations are presented regarding the inclusion of F-Gens in Higher Education in the country, highlighting the institutional collaboration process for minimizing the tensions between dominant and dominated in the scientific field.

Keywords: First-generation student. F-Gen. Higher Education. PNS/IBGE.

\section{Introdução}

A educação, por si só, está em constante evolução, ou pelo menos deveria estar, diante dos desafios que pairam nossa sociedade. Nesse sentido, a educação superior vem, nas últimas décadas, tendo suas formas de acesso alteradas, quer seja com a implementação de programas de ações afirmativas quer seja com novas métricas, tais como o Exame Nacional de Ensino Médio (Enem). O ENEM, associado ao Sisu, oportuniza ao candidato escolher a instituição de ensino superior (IES) e curso de seu desejo, acordado obviamente com a nota obtida. As vagas oferecidas por via de programas de ações afirmativas, também associadas à nota do Enem, oportunizam o acesso de grupos tidos como em "desvantagens iniciais" a ingressarem nesse grau de ensino. Entende-se aqui, "desvantagens iniciais, como aquelas que existem independentes do querer de cada um, tais como raça, sexo, idade, deficiências, família ou situação socioeconômica" (ROEMER, 1998; FELICETTI e MOROSINI, 2009, p. 12).

Dentre os programas de ações afirmativas, pode ser citado o de cotas em IES, como, por exemplo, as determinadas pela Lei 3.524/2000, que determinou a reserva de $50 \%$ das vagas ofertadas a cursos de graduação na Universidade Estadual do Rio de Janeiro - Uerj - e na Universidade Estadual do Norte Fluminense - Unenf - para candidatos oriundos de escolas públicas do estado, e mais tarde pela Lei 3.708/2001 que estabelece a reserva de $40 \%$ das vagas de tais universidades a candidatos negros e pardos (ALERJ, 2000, 2001). Outro programa de ações que merece destaque é o Programa Universidade para Todos - ProUni. Este, voltado às instituições privadas de educação superior com ou sem fins lucrativos, foi criado em 10 de setembro de 2004, via Medida Provisória n. ${ }^{\circ} 213$ que o instituiu. Posteriormente, essa Medida 
Provisória foi convertida na Lei n. ${ }^{\circ} 11.096$, de 13 de janeiro de 2005, sob a gestão do Ministério da Educação (BRASIL, 2005). O ProUni é destinado à concessão de bolsas de estudo integrais e parciais para estudantes de cursos de graduação e sequenciais de formação específica.

Dessa forma, em nenhum outro momento na história brasileira está registrado um número significativo de vagas para a educação superior para pessoas tidas como em "desvantagens iniciais". Tal fato instaura uma nova situação nas IES, ou seja, a diversidade do perfil estudantil, com uma pluralidade social, cultural, racial, cognitiva, ideológica, dentre outras no contexto acadêmico (FELICETTI, et al., 2019). Emergem, nesse ambiente, novas relações interpessoais e novos paradigmas.

Na compreensão dessa ambiguidade ainda presente, o olhar prospectivo busca ocupar um lugar. O olhar retrospectivo necessita servir de propulsor e delineador à tomada de decisões, isto é, o retrospectivo por si só já não faz mais sentido, uma vez que a ele somente se deter não resulta em avanços educacionais. $\mathrm{O}$ olhar retrospectivo necessita servir de suporte para apoiar novos fazeres em educação; suporte às medidas prospectivas, quando ele nos evidencia indicadores de ações a serem tomadas.

Nesse contexto, coloca-se em tela o olhar prospectivo acerca do novo perfil estudantil na educação superior, mais atentamente ao estudante de primeira geração (P-Ger). Para tal, este artigo discute, com fundamento em pesquisa bibliográfica, o conceito de estudante de primeira geração (P-Ger) e o de geração contínua C-Ger e suas características. Num segundo momento analisa, de forma inédita, os dados dos P-Ger, em fonte oficial da Pesquisa Nacional da Saúde - PNS - do Instituto Brasileiro de Geografia e Estatística - IBGE - de 2013 e conclui com considerações que possam auxiliar os P-Ger a integralizar o seu curso de graduação, destacando a questão da colaboração, basicamente, na perspectiva institucional e com a sua comunidade.

\section{Estudos brasileiros envolvendo diferentes perfis estudantis}

Nessa acepção, estudos que envolvem o perfil de estudantes na educação superior brasileira têm um conjunto diversificado de interesses. Entre eles os que abordam estudantes com necessidades especiais, especificamente surdos (CHIACCHIO, 2014; COLACIQUE, 2013; LIMA, 2012), deficiência visual (CARVALHO, 2001), de baixa renda (PERDIGÃO, 2012; 2016), de minorias étnicas (MAIA, 2007; GIANEZINI, 2014), os que abordam o Programa 
Universidade para Todos (MONGIM, 2010; FELICETTI, 2011; COSTA, 2012; FELICETTI e CABRERA, 2018) e os de primeira geração, mesmo que indiretamente (MELLO NETO, 2015; FIGUEIREDO, 2015; PRETTO, 2015; VALENTIM, 2012).

O Censo da Educação Superior de 2016 (INEP, 2018) apresenta as matrículas em cursos de graduação presenciais e a distância envolvendo algumas características dos estudantes, entre elas o sexo, cor/raça, faixa etária e necessidade especial. No entanto, não apontam outros aspectos atinentes aos matriculados nesse grau de ensino. Já nos dados apresentados acerca do Exame Nacional de Desempenho dos Estudantes (Enade), além de apresentarem dados sobre cor/raça, sexo, há questões no questionário do estudante que permitem conhecer um pouco melhor o perfil dos estudantes, então concluintes da educação superior brasileira. Entre tais perguntas que o compõem, tem-se a possibilidade de identificar quem é ou não de primeira geração.

Felicetti, Morosini e Cabrera (no prelo) identificaram em análise aos microdados do Enade que:

Do ENADE-2015, participaram 549.487 concluintes dos quais $32,4 \%$ foram considerados estudantes de P-Ger. Em 2016, participaram do ENADE 216.044, dos quais 38,8\% eram de primeira geração. Do ENADE - 2017, participaram 537.436 concluintes, dos quais $34,1 \%$ corresponderam a estudantes de primeira geração, ou seja, não tinham nenhum membro da família com curso superior, quer seja pai, mãe ou outro grau de parentesco. Foram identificadas as respostas que assinalavam a escolaridade do pai e da mãe com Ensino Superior - Graduação e cruzaram-se tais resultados com a terceira pergunta referente a ter algum familiar com curso superior. Observa-se com tais percentuais que, um novo perfil estudantil permeia o universo da Educação Superior e, o mais importante, egressos inseridos na sociedade, ou seja, egressos de P-Ger. Além disso, as três questões do Questionário do Estudante, permitem inferir que no contexto brasileiro, estudante de primeira geração é aquele que não tem, em sua família, alguém com curso superior (FELICETTI, MOROSINI E CABRERA, 2019, no prelo).

Assim, este estudo toma como definição de estudante de primeira geração no contexto brasileiro, aquele que não tem em sua família alguém com curso superior, ou seja, não se limita apenas ao pai ou à mãe, mas qualquer grau de parentesco ${ }^{1}$. Nessa direção e de acordo com o Centro Nacional de Estatística Educacional dos Estados Unidos, estudantes de primeira "são definidos 
como estudantes cujos pais não têm nenhum tipo de Educação Superior ou têm algum nível educacional inferior ao de Educação Superior" (REDFORD e HOYER, 2017, p. 3). Estudante de geração contínua é definido pelo mesmo Centro como aqueles que pelo menos um dos pais possui a educação superior.

Segundo Umbricht (2012), estudantes de primeira geração, quando comparados com os de geração contínua, tendem a ser diferentes, principalmente no que se refere ao quesito financeiro. Estudantes de P-Ger são menos propensos a terminarem a graduação, o que os torna menos propensos de terem melhores salários, o que torna menos provável que seus filhos frequentem uma faculdade (MCDONOUGH, 1997). Outros estudos mostraram que os estudantes de P-Ger são mais propensos a serem do sexo feminino e menos propensos a serem caucasianos (NUNEZ e CUCCARO-ALAMIN, 1998). Isso é um sinalizador de que estudante de P-Ger é mais propenso a ser oriundo de grupos em "desvantagens iniciais", o que evidencia a relevância de programas de ações afirmativas para esse grupo da população. Os referidos autores apontam que os estudantes de baixa renda e oriundos de grupos minoritários (alunos egressos do ensino público, afrodescendentes, indígenas, portadores de deficiência física e outros) tendem a ter resultados piores do que seus pares de baixa renda e não minoritários.

Dos estudos brasileiros, até então encontrados, que tiveram estudantes de P-Ger envolvidos, somente Mello Neto (2015) teve como condição serem seus entrevistados egressos de primeira geração. Os demais (FIGUEIREDO, 2015; PRETTO, 2015; VALENTIM, 2012; FELICETTI, 2011) encontraram entre seus participantes, nas pesquisas realizadas, a condição de serem os primeiros da família a estarem cursando a educação superior ou serem dela egressos. Os autores supracitados evidenciam um forte destaque na identificação dada por seus entrevistados ou participantes de serem os primeiros da família a estarem nessa condição. O destaque é posto tanto em depoimento às entrevistas como nos questionários respondidos. Nessa direção:

1 Nos USA, a P-Ger, no original F-Gen - First generation -, destaca dois estudos realizados por pesquisadores clássicos do país - Engle e Tinto (2008) e Pascarella, Pierson, Wolniak e Terezini (2003). Para os primeiros, F-Gen refere-se a indivíduos que não têm nenhum de seus pais ou responsáveis com quatro anos da graduação concluídos. No segundo estudo, é considerada F-Gen aqueles estudantes de educação superior cujos pais não têm mais do que o ensino médio. Os autores apontam a íntima relação entre famílias de baixa renda e, como consequência, a frequência a IES não seletivas e a pouca integração ao sistema de educação pós-secundário. 
Ser o primeiro a graduar-se nesse nível de ensino representa, para toda a família, quer direta ou indiretamente uma mudança de perspectivas e posturas diante dos mais variados aspectos, entre eles a visão de mundo que se amplia, que vai além das cercanias. O graduado passa a ser a referência na família. De certa forma acabei me tornando um "modelo" a ser seguido por outros membros da família, pois sou o primeiro formado de minha família! Outra resposta neste sentido: Sou o primeiro da família a se formar no curso superior e depois de mim outros familiares começaram a estudar (FELICETTI, CABRERA e MOROSINI, 2014, p. 29).

Entender o percurso formativo de um estudante de P-Ger é analisar a importância do capital cultural, econômico e social que o envolve no universo acadêmico. A ausência do capital econômico é um limitador à sua permanência na educação superior; no entanto, aspectos como facilidade de comunicação no ambiente acadêmico e a boa interação com professores, funcionários e seus pares constituem-se como contributivos ao sucesso escolar; o apoio da família ao estudante em seu percurso acadêmico contribui para o seu sucesso mesmo que seja somente em termos simbólicos.

Buscando suporte teórico para a compreensão dos achados anteriormente apontados, Bourdieu (1983, p. 10) afirma que o processo de acumulação de capital científico e as formas de sua reconversão são importantes, pois “[ [... a posse de capital científico tende a favorecer a aquisição de capital suplementar [...] no qual o capital inicial, representado pelo título escolar, tem um papel determinante".

Figueiredo (2015) teve em sua pesquisa estudantes da educação superior advindos de camadas populares, como participantes. A autora identificou, entre eles, os de primeira geração. Embora a trajetória desses estudantes enquanto na educação básica pública tenha sido de sucesso, somente na educação superior é que eles tomaram ciência da necessidade de estudar de forma disciplinada, metódica e autônoma, pois o contexto estudantil de outrora é muito diferente do de agora. Ela destaca que, embora os pais desses estudantes não tivessem formação acadêmica, eles foram os principais incentivadores para a conclusão dos estudos.

Os alunos entrevistados por Pretto (2015) são oriundos de classe econômica de baixo poder aquisitivo, que somente conseguiram acesso à IES por meio de políticas de ações afirmativas e, muitos deles, constituíram-se como os primeiros de suas famílias a ingressarem na educação superior. O autor conclui que o fato deles serem os primeiros da família a estar na universidade 
fez com que fossem um exemplo e estímulo aos demais membros da família a seguirem os estudos.

Valentim (2012), entre seus entrevistados egressos negros de uma universidade pública, também identificou os de primeira geração. Tal aspecto foi fortemente destacado pelos entrevistados.

Morosini e Griboski (2014) em estudo censitário sobre os concluintes da área da saúde no Brasil, constataram a presença significativa dos P-Ger na graduação. $\mathrm{O}$ conceito de $\mathrm{P}-\mathrm{Ger}$ adotado incluía formandos cujos pais não tinham a escolaridade concluída no terceiro grau. Em 2018, as autoras cruzaram informações entre aspectos de internacionalização e P-Ger, dos concluintes oriundos do Enade da área da Saúde (2013), e constataram a participação de estudantes de P-Ger, embora pequena, em processos de internacionalização, via mobilidade (MOROSINI e GRIBOSKI, 2018).

Em grande parte das pesquisas sobre P-Ger fica marcado o sentimento dos P-Ger de não se sentirem representados na cultura universitária da qual oficialmente fazem parte, em outras palavras, o meio acadêmico é novo para eles em todos os sentidos, especialmente por serem os primeiros da família a desbravarem tal contexto.

Nessa direção, Bourdieu e Passeron (2014) evidenciam, como ponto de partida a um planejamento pedagógico, a necessidade de se conhecer o perfil social dos estudantes, para de fato se poder falar em democratização real do conhecimento.

\section{Metodologia}

Os dados aqui analisados são oriundos do banco de dados da Pesquisa Nacional da Saúde - PNS - 2013, realizada pelo Instituto Brasileiro de Geografia e Estatística - IBGE. A PNS objetiva investigar diversas características sociodemográficas da população brasileira, tais como sexo, raça/cor, idade, estado conjugal, trabalho, renda, habitação, saúde, educação etc. Todas as regiões do país são contempladas pela pesquisa realizada no domicílio dos participantes, formando uma amostra representativa da população brasileira. Os dados explorados neste artigo dizem respeito à escolaridade das pessoas, os quais foram analisados objetivando identificar quais correspondem a estudantes ou egressos de P-Ger na educação superior.

Os 205.546 registros constantes no banco de dados foram filtrados de modo a criar uma variável de posicionamento capaz de identificar as gera- 
ções que vivem na mesma residência. Primeiramente foram desconsideradas as 8.739 pessoas que moravam sozinhas, pois não é possível identificar a escolaridade de sua geração pregressa. Após, as pessoas foram classificadas pelo grau de escolaridade assim definido: ensino fundamental e ensino médio, sem a separação de os dois graus de ensino serem completos, incompletos ou então em curso. Já para a educação superior, foi separado como: em curso, já graduado ou interrompido. Na sequência, somente as pessoas com mais de 15 anos de idade (144.597) permaneceram no banco de dados, visto que não houve nenhum participante com idade menor de 15 anos que estava frequentando ou tinha a escolaridade em nível superior. Foram encontradas 1.399 pessoas que não eram parentes, as quais também foram retiradas, restando até aqui 143.198 registros dos 205.546 iniciais. Foram excluídos os casais sem filhos e os domicílios unigeracionais, tais como irmão sem parentes no domicílio, pois não é possível saber o histórico escolar pregresso de seus familiares. Foram assim incluídos os participantes com curso superior (concluído, em curso ou interrompido) que conviviam com familiar de geração anterior, sendo possível identificar quais participantes eram os primeiros da família com curso superior (P-Ger) ou quais eram de geração contínua (C-Ger). Por fim, dos 143.198 registros, sobraram 6.867 pessoas com escolaridade de educação superior em curso, interrompida ou já concluída, possíveis de serem identificadas suas gerações anteriores. Foi usada a estatística descritiva e inferencial para a análise dos dados, o que marca o cunho quantitativo aqui usado. Foram comparados os grupos P-Ger e C-Ger.

\section{Análise e discussão dos dados}

Como pode ser observado na Tabela 1, dos 6.867 residentes com alguma escolaridade relacionada a nível superior, 4.891 (71,22\%) correspondem a pessoas de primeira geração a frequentarem a educação superior, dos quais $394(81,40 \%)$, de um total de 484, estavam com os estudos interrompidos, ou seja, iniciaram, mas não deram continuidade; dos 3.499 que estavam cursando a educação superior quando da pesquisa, 2.459 (70,28\%) eram de P-Ger; e dos 2.884 que já haviam concluído, $2.038(76,67 \%)$ eram de primeira geração $(\mathrm{p}<0,001)$. Tais resultados evidenciam um grande número de pessoas de $\mathrm{P}-\mathrm{Ger}$ frequentando o universo acadêmico em relação aos de geração contínua, ou seja, em relação àquelas pessoas que têm algum familiar com tal escolaridade. 
TABELA 1 - FREQUÊNCIA DE ESCOLARIDADE E O FATO DE OS PARTICIPANTES SEREM DE GERAÇÃO CONTÍNUA OU DE PRIMEIRA GERAÇÃO

\begin{tabular}{cccc}
\hline ESCOLARIDADE & C-Ger & P-Ger & Total \\
& Fr. $(\%)$ & Fr. $(\%)$ & Fr. $(\%)$ \\
\hline Superior concluído & $846(29,33)$ & $2.038(76,67)$ & $2.884(42,00)$ \\
Superior em curso & $1.040(29,72)$ & $2.459(70,28)$ & $\mathbf{3 . 4 9 9}(\mathbf{5 0 , 9 5})$ \\
Superior interrompido & $90(18,60)$ & $394(81,40)$ & $\mathbf{4 8 4}(\mathbf{7 , 0 5})$ \\
TOTAL & $1.976(28,78)$ & $4.891(71,22)$ & $\mathbf{6 . 8 6 7}(\mathbf{1 0 0})$ \\
\hline
\end{tabular}

FONTE: elaborado pelos autores com base no PNS - $2013(\mathrm{p}<0,001)$.

Na Tabela 2 que segue é possível observar que há maior representatividade de pessoas de P-Ger do sexo feminino, com 2.877 (73,86\%) do universo de 3.895, do que pessoas do sexo masculino de P-Ger, com 2.014 (67,77\%) do total de 2.972 homens. Embora as matrículas na educação superior brasileira estejam vários anos tendo o maior número representado por mulheres (INEP, $2009 ; 2010 ; 2011 ; 2012 ; 2013 ; 2014 ; 2015 ; 2016 ; 2017)$, as análises aqui realizadas evidenciam que há relação estatisticamente $(\mathrm{p}<0,001)$ significante entre mulheres de P-Ger e as de C-Ger, ou seja, a probabilidade de mulheres de P-Ger ingressarem na educação superior é maior que as de C-Ger. 
TABELA 2 - CARACTERÍSTICAS SOCIODEMOGRÁFICAS DOS PARTICIPANTES QUANTO AO FATO DE SEREM DE GERAÇÃO CONTÍNUA OU DE PRIMEIRA GERAÇÃO

\begin{tabular}{|c|c|c|c|c|}
\hline CARACTERÍSTICAS & $\begin{array}{l}\text { C-Ger } \\
\text { Fr.(\%) }\end{array}$ & $\begin{array}{c}\text { P-Ger } \\
\text { Fr.(\%) }\end{array}$ & $\begin{array}{c}\text { Total } \\
\text { Fr.(\%) }\end{array}$ & $\mathbf{p}$ \\
\hline SEXO & & & & \\
\hline Feminino & $1.018(26,14)$ & $2.877(73,86)$ & $3.895(56,72)$ & \multirow{2}{*}{$<0,001$} \\
\hline Masculino & $958(32,23)$ & $2.014(67,77)$ & $2.972(43,28)$ & \\
\hline $\begin{array}{c}\text { IDADE } \\
\text { (anos } \pm \text { Desv.Pad) }\end{array}$ & $25,7 \pm 7,49$ & $28,7 \pm 10,07$ & $27,2 \pm 8,78$ & $<0,001$ \\
\hline $\begin{array}{c}\text { ESTADO } \\
\text { CONJUGAL }\end{array}$ & & & & $<0,001$ \\
\hline Casado & $221(29,55)$ & $527(70,45)$ & $748(10,89)$ & \multirow{4}{*}{$<0,001$} \\
\hline Divorciado & $68(16,63)$ & $341(83,37)$ & $409(5,96)$ & \\
\hline Solteiro & $1.677(29,64)$ & $3.980(70,36)$ & $5.657(82,38)$ & \\
\hline Viúvo & $10(18,87)$ & $43(81,13)$ & $53(0,77)$ & \\
\hline \multicolumn{5}{|l|}{ RAÇA } \\
\hline Amarela & $22(36,07)$ & $39(63,93)$ & $61(0,89)$ & \multirow{5}{*}{$<0,001$} \\
\hline Branca & $1.283(33,46)$ & $2.552(66,54)$ & $3.835(55,85)$ & \\
\hline Indígena & $5(27,78)$ & $13(72,22)$ & $18(0,26)$ & \\
\hline Parda & $578(22,93)$ & $1.943(77,07)$ & $2.521(36,71)$ & \\
\hline Preta & $88(20,37)$ & $344(79,63)$ & $432(6,29)$ & \\
\hline TOTAL & $1.976(28,78)$ & $4.891(71,22)$ & $6.867(100,00)$ & \\
\hline
\end{tabular}

FONTE: elaborado pelos autores com base no PNS - 2013. Desv. Pad= Desvio Padrão.

A média de idade foi significativamente maior entre os de P-Ger $(\mathrm{p}<0,001)$, ou seja, estudantes de P-Ger tendem a serem mais velhos que os seus pares. Com relação ao estado conjugal, é possível identificar que, entre as pessoas de 
P-Ger, a maior representatividade está para os divorciados (341) e viúvos (43), correspondendo respectivamente a $83,37 \%$ dos 409 e $81,13 \%$ dos 53 . Houve relação estatisticamente significante $(\mathrm{p}<0,001)$ entre ser $\mathrm{C}-\mathrm{Ger}, \mathrm{P}-\mathrm{Ger}$ e a característica "estado conjugal".

Na Tabela 2 também é possível observar a distribuição no que concerne à raça indicada no banco de dados. Destaca-se aqui os percentuais de $72,22 \%$, $77,07 \%$ e $79,63 \%$, correspondentes, respectivamente, a indígena, parda e preta, no âmbito da primeira geração. Tais resultados evidenciam que pessoas de grupos minoritários, tais como as raças indígenas, pardas e pretas, têm tido uma representação maior de $\mathrm{P}-\mathrm{Ger}$ que seus pares $\mathrm{C}$-Ger. Isso pode estar relacionado aos programas de ações afirmativas implementados no contexto brasileiro. Houve relação estatisticamente significante $(p<0,001)$ entre ser C-Ger, P-Ger e a característica "raça".

Os dados aqui analisados apontam um alto número de estudantes de primeira geração nos três âmbitos de escolaridade, ou seja, aos que estão em curso na educação superior, aos que já concluíram e também, embora em quantidade menor, aos que estão com os estudos interrompidos. Tais dados evidenciam para além de um novo perfil nesse grau de ensino, mas sinalizam diferenças no perfil de pessoas na sociedade. É uma nova classe de graduados a viverem em sociedade. Isso é evidente e se acentua mais diante dos dados apresentados na Tabela 2, na qual se observa um percentual acima de $70 \%$ para estudantes de $\mathrm{P}$-Ger, quando se trata indígenas, pardos e negros, mostrando mais uma vez a inserção de grupos tidos com em "desvantagens iniciais", tornando explícita a democratização da educação superior. Obviamente, tais números, se comparados ao montante da população brasileira, são ínfimos, no entanto sinalizam mudanças, e em longo prazo melhorias, no que diz respeito à escolarização da população brasileira, pois, como afirmam Felicetti e Cabrera (2017), está havendo a construção de um novo capital cultural que pode refletir nas futuras gerações, desencadeando melhores perspectivas sociais e econômicas ao país.

\section{Frente ao novo perfil P-Ger: políticas institucionais colaborativas em cena}

$\mathrm{Na}$ busca de proposições para sincronizar as diferenças entre os perfis tradicionais e os novos perfis de estudantes da educação superior, alguns estudos (BECKER, KROBEL, TUCKER, 2010) têm como consenso a necessidade de colaboração entre diversos setores da instituição universitária/comunidade. As 
políticas para o atendimento dessas metas não se restringem ao patamar nacional. Recordemos que a educação superior no Brasil é fortemente gestada e gerida pelo Estado, mas a perspectiva institucional e suas relações em nível de comunidade são assaz definidoras. Estudos de organizações não lucrativas têm proposto medidas para a obtenção da colaboração (MATTESSICH, MURRAY e MONSEY, 2001), que foram agrupadas em seis categorias (REDFIELD, 2011) a seguir sintetizadas:

I. Meio Ambiente: refere-se ao contexto social e geográfico no qual as alianças estratégicas se desenvolvem. Necessita de um ambiente político e social favorável à colaboração, que respeite o histórico de colaboração ou cooperação já existentes na organização/comunidade e busque a construção/consolidação de grupo colaborativo líder;

II. Grupos colaborativos: pessoas e/ou culturas de organizações que são fundamentados em respeito mútuo, compreensão e confiança, caracterizados por membros de diversos níveis, comprometidos com o projeto de inclusão e percebendo a colaboração como seu autointeresse;

III. Processo/Estrutura: refere-se à gestão, ao processo de tomada de decisão, ao sistema operacional dos esforços para construir a aliança para a colaboração. Os membros compartilham participação no processo e nos resultados, com flexibilidade e adaptabilidade às mudanças. Há o desenvolvimento de papéis, políticas e diretrizes claras e as múltiplas camadas da organização participam do processo de tomada de decisão;

IV. Comunicação: caracteriza-se por ser aberta e frequente, formal e informal, com links de comunicação disponíveis;

V. Propósito da colaboração: refere-se às razões para o desenvolvimento da colaboração, com metas e objetivos concretos e atingíveis. Com uma visão compartilhada para atingir um propósito único;

VI. Recursos: refere-se à existência ou captação de financiamento suficiente para a colaboração, congregando liderança e capacidade de pensamento estratégico.

Com a proposição dessas categorias, não se olvida que o campo científico é uma arena conflitiva marcada por tensões entre os que dominam e os que buscam uma ascensão; entre os que possuem e estão integrados a uma cultura 
universitária presente há séculos e aqueles que estão tendo acesso a essa cultura, mais recentemente, mas não se sentem representados nela.

Objetiva-se com tais proposições buscar formas que construam a colaboração para que dominantes e dominados minimizem suas arestas e construam um convívio e compreensão de que hoje, no país, há que se buscar uma nova cultura universitária, que represente os indivíduos que nela estão.

\section{Algumas considerações}

Bourdieu (1983) afirma que o campo científico, aqui entendido como o da educação superior, é um campo de lutas para o domínio da autoridade científica, compreendida como "capacidade técnica e poder social; ou monopólio da competência científica, enquanto capacidade de falar e de agir legitimamente (isto é, de maneira autorizada e com autoridade), que é socialmente outorgada a um agente determinado" (p. 122-123).

Nessa arena, os dados em análise neste artigo evidenciam um novo perfil estudantil que começa a se munir do poder social, isto é, do poder do capital educacional que se estabelece aos estudantes P-Ger. Há, portanto, a busca de uma alteração do status quo, e dominantes e dominados entram em choque a partir, basicamente, da violência simbólica, perpassada não somente por movimentos de manutenção, mas pela alteração desse status com o novo perfil estudantil em tela neste artigo.

O domínio do campo científico, e, consequentemente, da autoridade científica, reflete a estrutura de distribuição do capital científico e está objetivada nas instituições e incorporada nas disposições como, por exemplo, habitus.

Frente a essa teorização simplificada, juntamente aos estudos de Felicetti, Morosini e Cabrera (2019 no prelo), apontam-se fatores representativos à permanência ou não dos $\mathrm{P}-G e r$ na educação superior. $\mathrm{O}$ não se sentir parte da cultura universitária dominante é um fator a ser considerado e tomado como ponto inicial no acompanhamento ao estudante. Nessa direção, destaca-se novamente Bourdieu (1983), quando ele afirma:

$\mathrm{Na}$ luta que os opõem, os dominantes e os pretendentes - os novatos recorrem a estratégias antagônicas profundamente opostas em sua lógica e no seu princípio. Os interesses [...] que os motivam e os meios que eles podem colocar em ação para satisfazê-los dependem estreitamente de 
sua posição no campo [...]. Os dominantes consagram-se às estratégias de conservação, visando assegurar a perpetuação da ordem científica estabelecida com a qual compactuam (p. 137).

Da mesma forma, os novatos buscam estratégias de subversão para conseguirem espaço no ambiente universitário, sendo reconhecido que alterar a ordem constituída é muito mais difícil e complexo do que buscar seguir os padrões já existentes e dados como os certos. Bourdieu também refere as estratégias de sucessão que, teoricamente, poderiam estar mais linkadas aos C-Ger, pois lhes garantiriam, "[...] ao término de uma carreira previsível, os lucros prometidos, pelo preço de inovações circunscritas aos limites autorizados" (BOURDIEU, 1983, p. 138).

Para compor o quadro de compreensão que fundamenta o presente artigo, analisamos os dados da realidade brasileira do PNS/IBGE/2013, quanto a sexo, idade, estado conjugal e raça dos estudantes ou egressos de P-Ger. Essa nova composição, diversa do tradicional perfil do estudante universitário, remete a novas exigências e necessidades no contexto da educação superior. A maneira de ministrar aula ou fazer gestão requer novos fazeres e seres. Requer um olhar, um entender e o almejar aliado às necessidades desse alunado, de modo a lhe proporcionar a permanência até a integralização do curso de graduação.

Para finalizar, procuramos destacar a importância das políticas, no caso específico, em nível de instituição, que considerem essas configurações e que elaborem condições para que se estabeleçam colaborações que possam levar ao sucesso (integralização do curso) do P-Ger.

Enfim, a questão P-Ger, refletora de contexto emergente da educação superior, é presente e vem desafiando a democratização desse grau de ensino, despontando como um dos temas necessários de estudos e pesquisas no país.

\section{REFERÊNCIAS}

BALERJ - Assembleia Legislativa do Estado do Rio de Janeiro, 2000. LEI $N^{\circ} 3524$, DE 28 DE DEZEMBRO DE 2000. Dispõe sobre os Critérios de Seleção e Admissão de Estudantes da Rede Pública Estadual de ensino em Universidades Públicas Estaduais e dá outras Providencias. Disponível em: http://www.alerj.rj.gov.br. Acesso em: 02 jan. 2019.

ALERJ- Assembleia Legislativa do Estado do Rio de Janeiro, 2001. LEI $N^{\circ} 3708, D E$ 09 DE NOVEMBRO DE 2001. Institui cota de até $40 \%$ (quarenta por cento) para as 
populações negra e parda no acesso à Universidade do Estado do Rio de Janeiro e à Universidade Estadual do Norte Fluminense, e dá outras providências. Disponível em: http://www.alerj.rj.gov.br. Acesso em: 02 jan. 2019.

BECKER, K.; KROBEL, K.; TUCKER, B. Understanding and engaging under-resourced college students. HIghlands-TX: aha! Process Inc, 2010

BOURDIEU, P. O campo científico. In: ORTIZ, R. (org). Pierre Bourdieu sociologia. São Paulo: Ática, 1983.

BOURDIEU, P; PASSERON, J. Os herdeiros: os estudantes e a cultura. Florianópolis: Editora da UFSC, 2014.

BRASIL. Lei no 11.096, de 13 de janeiro de 2005. Institui o Programa Universidade para Todos - PROUNI, 2005. Presidência da República. Brasília, DF: Diário Oficial da União. Disponível em: http://www.planalto.gov.br/ccivil_03/_Ato2004-2006/2005/LEI/ L11096.htm. Acesso em: 02 jan. 2019.

CHIACCHIO, S. S. R. Saberes Docentes Fundamentais para a Promoção da Aprendizagem do Aluno Surdo no Ensino Superior Brasileiro. 2014. 219 f. Tese (Doutorado em Educação), Pontifícia Universidade Católica de São Paulo, São Paulo, 2014.

COLACIQUE, R. Acessibilidade para surdos na cibercultura: os cotidianos nas redes e na educação superior online. 2013. 166 f. Dissertação (Mestrado em Educação), Universidade do Estado do Rio de Janeiro, Rio de Janeiro, 2013.

CARVALHO, J. O. F. Soluções tecnológicas para viabilizar o acesso do deficiente visual a educação à distância no ensino superior. 245 f. Tese (Doutorado em Engenharia Elétrica e de Computação) - Universidade Estadual de Campinas, Campinas, 2001. Disponível em: http://repositorio.unicamp.br/bitstream/REPOSIP/260232/1/Carvalho_JoseOscarFontaninide_D.pdf. Acesso em: 12 jan. 2019.

COSTA, F. S. O ProUni e seus egressos: uma articulação entre educação, trabalho e juventude. $201 \mathrm{f}$. Tese (Doutorado em Educação: Currículo) - Pontifícia Universidade Católica de São Paulo, São Paulo, 2012.

ENGLE, J. \& TINTO, V. Moving beyond access: College success for lower income, first generation students. Washington: the Pell Institute for the study of opportunitty in Higher education, 2008.

FELICETTI, V. L.; MOROSINI, M. C. Equidade e iniquidade no ensino superior: uma reflexão. Ensaio: Avaliação e Políticas Públicas em Educação, Rio de Janeiro, v. 17, n. 62, p. 9-24, jan./mar. 2009.

FELICETTI, V. L. Comprometimento do estudante: um elo entre aprendizagem e inclusão social na qualidade da educação superior. 298 f. Tese (Doutorado em Educação) - Pontifícia Universidade do Rio Grande do Sul, Rio Grande do Sul, 2011.

FELICETTI, V. L.; CABRERA, A. F.; MOROSINI, M. C.. Aluno PROUNI: Impacto Na Instituição de Educação Superior e na Sociedade. Revista Iberoamericana de Educación 
Superior (RIES), n. 13, v. 2014, p. 21-39. Disponível em: http://ries.universia.net/index. php/ries/article/view/311/pdf_75. Acesso em: 10 nov. 2018.

FELICETTI, V. L.; CABRERA, A. F. Trajectory in Higher Education: ProUni in Focus. Ensaio: Avaliação e Politicas Públicas em Educação, Rio de Janeiro, v.25, n. 95, p. 308329, abr./jun. 2017. Disponível em: http://doi.org/10.1590/S0104-40362017002501056. Acesso em: 10 nov. 2018.

. Access to Higher Education: ProUni in Focus. Arquivos Analíticos de Políticas Educativas Arquivos Analíticos de Políticas Educativas, V.26, n.39. 2018. Disponível em: http://dx.doi.org/10.14507/epaa.26.3289. Acesso em: 10 nov. 2018.

FELICETTI, V. L.; PEREIRA, M. A. C.; SILVA, G. B.; SZEZECINSKI, Antonio F. M. Contextos Emergentes na Educação Superior: dois universos, alunos de primeira geração e alunos surdos. Porto Alegre: EdPucrs, 2019.

FELICETTI, V. L.; MOROSINI, M. C.; CABRERA, A. F. Estudante de Primeira Geração (P-Ger) na Educação Superior Brasileira. (2019 no prelo)

FIGUEIREDO, A. C. Processos de interação e afiliação à vida acadêmica de estudantes de camadas populares no contexto da expansão universitária. 2015. 175f. Dissertação (Mestrado em Educação) - UFMG, Belo Horizonte, 2015.

GIANEZINI, K. J. M. D. Educação e sociedade: a expansão do ensino superior jurídico e o acesso de minorias étnicas. Tese (Doutorado em Educação) - Universidade Federal do Rio Grande do Sul, Porto Alegre, 2014. Disponível em: https://www.lume.ufrgs.br/ bitstream/handle/10183/79438/000900545.pdf;sequence=1. Acesso em: 12 jan. 2019.

INEP. Sinopse Estatística da Educação Superior, 2009. Disponível em: http://portal.inep. gov.br/web/guest/sinopses-estatisticas-da-educacao-superior. Acesso em: 02 jan. 2019.

. Sinopse Estatística da Educação Superior, 2010. Disponível em: http://portal. inep.gov.br/web/guest/sinopses-estatisticas-da-educacao-superior. Acesso em: 02 jan. 2019.

. Sinopse Estatística da Educação Superior, 2011. Disponível em: http://portal. inep.gov.br/web/guest/sinopses-estatisticas-da-educacao-superior. Acesso em: 02 jan. 2019.

. Sinopse Estatística da Educação Superior, 2012. Disponível em: http://portal. inep.gov.br/web/guest/sinopses-estatisticas-da-educacao-superior.

Acesso em: 02 jan. 2019.

. Sinopse Estatística da Educação Superior, 2013. Disponível em: http://portal. inep.gov.br/web/guest/sinopses-estatisticas-da-educacao-superior. Acesso em: 02 jan. 2019.

. Sinopse Estatística da Educação Superior, 2014. Disponível em: http://portal. inep.gov.br/web/guest/sinopses-estatisticas-da-educacao-superior. Acesso em: 02 jan. 
2019.

. Sinopse Estatística da Educação Superior, 2015. Disponível em: http://portal. inep.gov.br/web/guest/sinopses-estatisticas-da-educacao-superior. Acesso em: 02 jan. 2019.

. Sinopse Estatística da Educação Superior, 2016. Brasília: Inep, 2018. Disponível em: http://portal.inep.gov.br/web/guest/sinopses-estatisticas-da-educacao-superior. Acesso em: 02 jan. 2019.

. Sinopse Estatística da Educação Superior, 2017. Disponível em: http://portal. inep.gov.br/web/guest/sinopses-estatisticas-da-educacao-superior. Acesso em: 02 jan. 2019.

LIMA, P. R. E. A de. O acesso e permanência de indivíduos surdos no ensino superior. 2012. 117 f. Dissertação (Mestrado em Educação), Pontifícia Universidade Católica de São Paulo. São Paulo, 2014.

MAIA, M. G. B. Políticas de acesso à educação superior: o sistema de cotas para negros. 142 f. Dissertação (Mestrado em Educação) - Pontifícia Universidade Católica do Paraná, Curitiba, 2007. Disponível em: bdtd.ibict.br/vufind/Record/P_PR_002156c 40a9d9c16b86b44b993b294fc . Acesso em: 06 jan. 2019.

MATTESSICH, P., MURRAY-CLOSE, M., \& MONSEY, B. Wilder Collaboration Factors Inventory. St. Paul, MN: Wilder Research, 2001.

MCDONOUGH, P. M. Choosing colleges. How social class and schools structure opportunity. State University of New York Press, State University Plaza, Albany. NY $12246,1997$.

MELLO NETO, R. D. Não vou me adaptar: um estudo sobre os bolsistas pernambucanos. Universidade de São Paulo, São Paulo, 2015.

MONGIM, A. B. Título universitário e prestígio social. Percursos sociais de estudantes beneficiários do ProUni. 2010. 176 f. Tese (Doutorado em Antropologia) - Universidade Federal Fluminense, Rio de Janeiro, 2010.

MOROSINI, M., GRIBOSKI, C. Políticas afirmativas no Brasil e a persistência da primeira geração de formandos na área da Saúde. In: XXXII International Congress of the Latin American Studies. Association. Chicago. Anais ... LASA 2014: Papers 2014. P. $1-8,2014$. Acesso restrito.

MOROSINI, M.; GRIBOSKI, C. Internacionalização e concluintes da graduação no Brasil: perfil demográfico e as políticas democratizantes. In SOUSA, V., BOTELHO, A. GRIBOSKI, C. (Orgs). Acesso e permanência na expansão da Educação Superior. - Anápolis-GO: Ed. UEG, 2018. p. 238 - 251.

NUNEZ, A.; CUCCARO-ALAMIN, S. First Generation Students: Undergraduates Whose Parents Never Enrolled in Postsecondary Education. Washington, DC: U.S. Department of Education, National Center for Education Statistics (NCES), 1998. 
PASCARELlA, E. T.; WOLNIAK. G. C.; PIERSON, C. T. \& TEREZINI, P. T. Experiences and outcomes of first-generation students in community colleges. Journal of College Student Development, 44(3), 420 - 429, 2003.

PERDIGÃO, D. A. O Dilema de Jusciléia: Formação Superior e (Im)Possibilidades de Reinserção Profissional. TAC, Rio de Janeiro, v. 2, n. 1, pp. 50-55, Jan./Jun. 2012. Disponível em: http://www.anpad.org.br/tac. Acesso em: 05 de nov. 2018.

PERDIGÃO, D. A. O apelo simbólico da educação superior como emancipadora do aluno proveniente de famílias de baixa renda. IV Congresso Brasileiro de Estudos Organizacionais - Porto Alegre, RS, Brasil, 19 a 21 de Outubro de 2016. Disponível em: https://anaiscbeo.emnuvens.com.br/cbeo/article/view/63. Acesso em: 05 de nov. 2018.

PRETTO, F. Ações afirmativas na FACED/UFRGS: um estudo a partir dos alunos que acessam o LIES. 2015. 166f. Dissertação (Mestrado em Educação) - UFRGS, Porto Alegre, 2015.

REDFIELD, M. Twenty Ingredients for a Successful Collaboration: Research clarifies what's needed when planning a strategic alliance. Nonprofit World, Volume 29, Number 2, March/April. Livonia: the Society for Nonprofit Organizations, 2011.

REDFORD, J.; HOYER, K. M. First-generation and continuing-generation college students: A comparison of High School and Postsecondary Experiences. US Department of Education, NCES 2018-009, 2017. Disponível em: https://nces.ed.gov/ pubs2018/2018009.pdf. Acesso em: 15 de out. 2018.

ROEMER, J. E. Equalizing opportunities (in one country) for human development. University of California: Davies, 1998. Disponível em: http://siteresources.worldbank. org/INTPGI/Resources/13272_equalizing_opportunities_for_human_development.pdf. Acesso em: 15 de out. 2018.

UMBRICHT, M. R. First in, last out: time-to-degree of first-generation students. (Master of Science in Educational Organization and Leadership) University of Illinois at Urbana-Champaign, 2012

VALENTIM, D. F. D. Ex-alunos negros cotistas da UERJ: os desacreditados e o sucesso acadêmico. 2012. 234p. Tese (Doutorado) - Departamento de Educação, Pontifícia Universidade Católica do Rio de Janeiro, Rio de Janeiro, 2012.

Texto recebido em 12 de maio de 2019.

Texto aprovado em 17 de maio de 2019. 